\title{
The use of sodium DL-3-Hydroxybutyrate in severe acute neuro-metabolic compromise in patients with inherited ketone body synthetic disorders
}

Kaustuv Bhattacharya ${ }^{1,2^{*}}$ (D) Walid Matar ${ }^{3}$, Adviye Ayper Tolun ${ }^{4}$, Beena Devanapalli ${ }^{4}$, Sue Thompson ${ }^{1,2}$, Troy Dalkeith ${ }^{1,2}$, Kate Lichkus ${ }^{1,2}$ and Michel Tchan ${ }^{1,5}$

\begin{abstract}
Background: Ketone bodies form a vital energy source for end organs in a variety of physiological circumstances. At different times, the heart, brain and skeletal muscle in particular can use ketones as a primary substrate. Failure to generate ketones in such circumstances leads to compromised energy delivery, critical end-organ dysfunction and potentially death. There are a range of inborn errors of metabolism (IEM) affecting ketone body production that can present in this way, including disorders of carnitine transport into the mitochondrion, mitochondrial fatty acid oxidation deficiencies (MFAOD) and ketone body synthesis. In situations of acute energy deficit, management of IEM typically entails circumventing the enzyme deficiency with replenishment of energy requirements. Due to profound multi-organ failure it is often difficult to provide optimal enteral therapy in such situations and rescue with sodium DL-3-hydroxybutyrate (S DL-3-OHB) has been attempted in these conditions as documented in this paper.
\end{abstract}

Results: We present 3 cases of metabolic decompensation, one with carnitine-acyl-carnitine translocase deficiency (CACTD) another with 3-hydroxyl, 3-methyl, glutaryl CoA lyase deficiency (HMGCLD) and a third with carnitine palmitoyl transferase II deficiency (CPT2D). All of these disorders are frequently associated with death in circumstance where catastrophic acute metabolic deterioration occurs. Intensive therapy with adjunctive S DL-3OHB led to rapid and sustained recovery in all. Alternative therapies are scarce in these situations.

Conclusion: S DL-3-OHB has been utilised in multiple acyl co A dehydrogenase deficiency (MADD) in cases with acute neurological and cardiac compromise with long-term data awaiting publication. The use of S DL-3-OHB is novel in non-MADD fat oxidation disorders and contribute to the argument for more widespread use.

Keywords: Carnitine acyl-carnitine translocase deficiency (CACTD), 3-hydroxyl-3-methylglutaryl-CoA lyase deficiency (HMGCLD), Carnitine palmitoyl transferase II deficiency (CPT2D), Ketone body, 3-hydroxybutyrate, Fat oxidation

\footnotetext{
* Correspondence: Kaustuv.bhattacharya@health.nsw.gov.au

'Disciplines of Genetic Medicine and Child and Adolescent Health, University of Sydney, Sydney, Australia

${ }^{2}$ Genetic Metabolic Disorders Service, Sydney Children's Hospital Network, Children's Hospital at Westmead, Locked Bag 4001, Westmead, NSW 2145, Australia

Full list of author information is available at the end of the article
}

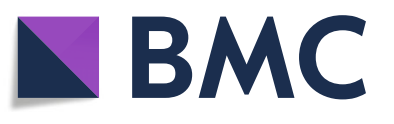

(c) The Author(s). 2020 Open Access This article is distributed under the terms of the Creative Commons Attribution 4.0 International License (http://creativecommons.org/licenses/by/4.0/), which permits unrestricted use, distribution, and reproduction in any medium, provided you give appropriate credit to the original author(s) and the source, provide a link to the Creative Commons license, and indicate if changes were made. The Creative Commons Public Domain Dedication waiver (http://creativecommons.org/publicdomain/zero/1.0/) applies to the data made available in this article, unless otherwise stated. 


\section{Introduction}

Mitochondrial fatty acid oxidation (MFAO) disorders comprise disorders that lead to impaired production of the ketone bodies in the liver. MFAO yields acetyl-Co A which condenses to form the ketone body acetoacetate [1]. The other ketone bodies (KB), 3-hydroxybutyrate and acetone are derived from acetoacetate. Failure to generate $\mathrm{KB}$ at times of physiological stress has catastrophic sequelae in MFAO and KB synthetic disorders [2]. In severe forms of these conditions, such as CACTD, HMGCL2 deficiency and CPT2D, life threatening encephalopathy, cardiomyopathy and arrythmias during metabolic decompensation are well recognised [3-8]. Chronic treatment generally utilises medium chain triglyceride (MCT) as an alternative energy source, but this would be ineffective in HMGCL2 deficiency [6, 9]. In acute metabolic decompensation, intravenous carbohydrate is used though adequate caloric supplementation sufficient to reverse catabolism is difficult to achieve. The three cases presented in this paper with CACTD, HMGLC2D and CPT2D were all cases in which catastrophic acute encephalopathy was progressing despite management with intravenous dextrose saline. Intervention with S DL-3-OHB reversed this course and led to sustained recovery in all. S DL-3-OHB has previously been used in MADD in similar critical situations leading to recovery but not in other fat oxidation disorders [10].

\section{Methods}

The use of S DL-3-OHBwas granted by our institution's therapeutic drug and ethics committee. In all cases notification of emergency administration and ongoing supply was made via the Special Access Scheme of the Australian Federal Government's Therapeutic Goods Administration (TGA.) The TGA serves as a similar regulatory body to the Food and Drugs Administration (FDA) in USA. This study has been approved by the Ethics Committee of Sydney Children's Hospitals' Network and informed consent was taken from the patient or carer as appropriate for age. The report comprises retrospective chart review.

Urinary organic acid levels were analysed qualitatively using gas chromatography mass spectrometry (GC/MS) (QP-2010 Ultra, Shimadzu Corp., Japan) after solvent extraction and trimethylsilyl derivatization of urine samples as previously described [11, 12]. Underivatized plasma acylcarnitine levels were analysed using ultrahigh performance liquid chromatography-tandem mass spectrometry (UPLC-MS/MS) (Xevo TQ-S Acquity UPLC, Waters, USA) [13, 14]. CPT II enzyme analysis on leucocytes and fibroblasts were based on a modified version of Demaugre et al., 1991 using non-radioactive substrates. Protein content was determined using bicinchoninic assay (BCA) $[15,16]$.

\section{Case I}

Case I is a female child of non-consanguineous Caucasian parents, born at term having a hypoglycaemic episode on day two of life. Despite increased feed frequency, she developed hypothermia on day three and was empirically managed as having sepsis with intravenous 10\% dextrose and antibiotics. On day 4, after expressed breast milk reintroduction, she became lethargic with an apnoeic episode and seizures. The blood gas demonstrated $\mathrm{pH} 7.51$ (7.35-7.45), pCO2 $23 \mathrm{mmHg}(32-45)$ with serum ammonia of $800 \mu \mathrm{mol} / \mathrm{L}(10-80)$. The baby was again placed nil by mouth, restarted $10 \%$ dextrose, administered a loading dose of phenobarbitone and was referred to a tertiary metabolic unit. The serum ammonia and blood gas returned to normal in $24 \mathrm{~h}$ without any adjunctive ammonia lowering therapy. Initial urine organic acids indicated significant medium and long chain dicarboxylic aciduria without evidence of ketones being produced, indicating a presumptive diagnosis of a long chain MFAO disorder. Initial feeds on day five comprised $90 \%$ glucose polymer and 10\% expressed breast milk with supplemental S DL-3$\mathrm{OHB}$ of $300 \mathrm{mg} / \mathrm{kg} /$ day (Special Products Ltd., UK - (Veriton Pharma)). On day six, the baby deteriorated with multi-organ failure comprising severe cardiac dysfunction with factional shortening 16\% (28-45), liver dysfunction and seizures, with her having feeds discontinue, anticonvulsants commence and being invasively ventilated.. However, S DL-3-OHB was continued at a dose of 600 $\mathrm{mg} / \mathrm{kg} /$ day. Brain MRI demonstrated extensive white matter changes (Fig. 1a). Carbohydrate and MCT based feeds (Polyjoule and Monogen respectively, Nutricia Ltd., USA) restricting long chain dietary fat $<5 \%$ of total energy intake were cautiously introduced on day seven per Table $1 \mathrm{a}$. Cardiac fractional shortening had improved to $41 \%$ on day nine and she continued to make steady improvement thereafter, being extubated on day nine and discharged home independently feeding on day twenty-three. She had normal early milestones of development and is currently aged 9 years attending normal mainstream school with additional support for attention deficit hyperactivity disorder and mild learning difficulties. There was recovery on brain MRI performed at 2 years of age (Fig. 1b). The diagnosis was subsequently confirmed with skin fibroblast fat oxidation flux studies indicative of either CACTD or CPT2D with leucocyte activity of CPT2 being normal (93\% activity of CPT2 relative to controls.) Subsequent molecular studies indicated c.326+1 delG mutation and c.50G > C variant of unknown significance of SLC25A20. Contemporary bedside ketone measurements were not performed.

\section{Case 2}

Case 2 was the second male child of nonconsanguineous Slovakian parents. He had an uneventful 
a

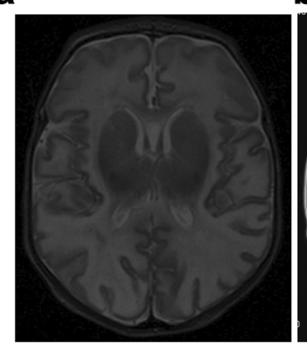

b

C
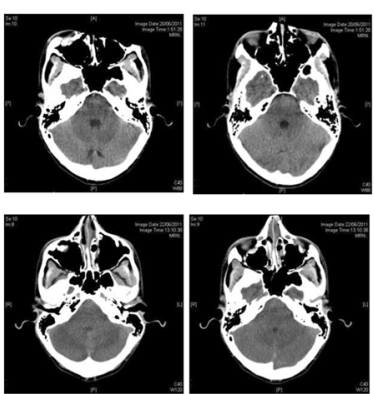

d

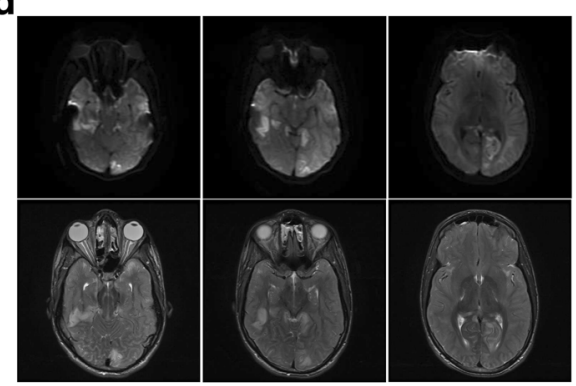

e
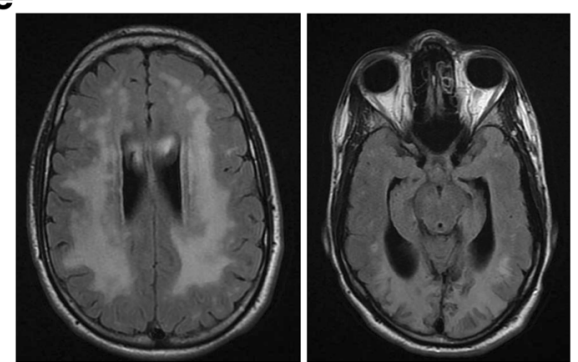

$\mathbf{f}$

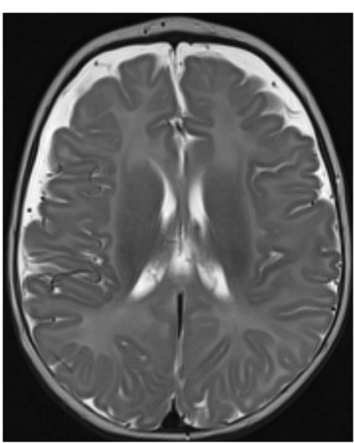

Fig. 1 a) Sagittal MRI Image of the brain on day 12 of case I with CACTD, indicating extensive abnormal $\mathrm{T} 2$ hyperintensity seen within the white matter of both cerebral hemispheres. b) T2 -weighted MRI of brain of case 1 at 16 months indicating mild white matter and cortical volume loss especially in the parietal region. Hyperintensity has substantially improved

birth and infancy, presenting after four months with hypoglycaemia after switching from breast milk to formula. HMGCL2D was diagnosed on the basis of typical biochemistry including gross elevation of urinary 3hydroxy-3-methlylglutarate. He was stabilised on a low protein and fat diet but was lost to follow up from age 1 year until the age of 16 . At this age he attended normal mainstream education with normal achievement. $\mathrm{He}$ presented to the local emergency department after $48 \mathrm{~h}$ of persistent vomiting, and was admitted into hospital with lethargy, disorientation and slurred speech. The baseline assessment noted that he had tachycardia, tachypnoea and a core of temperature of 34.7 degrees centigrade. His Glasgow Coma Scale (GCS) was 15. Initial biochemistry demonstrated $\mathrm{pH} 7.12$; Bicarbonate of 6.8 $\mathrm{mmol} / \mathrm{L}(18 \cdot 0-24 \cdot 0)$, lactate $16 \mathrm{mmol} / \mathrm{L}(0-2 \cdot 0)$, Base Excess $-20(-2.0$ to $+2 \cdot 0)$, Anion gap $29 \mathrm{mmol} / \mathrm{L}(8-18)$ with a blood glucose of $2 \mathrm{mmol} / \mathrm{L}$ (3.0-5.5). Acetoacetate level was subsequently reported as $0.07 \mathrm{mmol} / \mathrm{L}$ $(0.05-0.15)$ and betahydroxybutyrate $0.01 \mathrm{mmol} / \mathrm{L}$ (0.03-3.0). He was resuscitated with dextrose and normal saline boluses, treated with antibiotics and anti-viral agents and maintained on 5\% dextrose maintenance fluids. On day two of admission his consciousness level deteriorated with a GCS of 9, being unable to follow commands. He had three beats of clonus on his right side and bilateral extensor plantar responses. Pupils were noted to be reacting sluggishly. A brain CT showed confluent white matter hypodensity and evidence of small ventricles consistent with significantly raised intracranial pressure. Serum ammonia was elevated at $455 \mu \mathrm{mol} / \mathrm{L} \quad(<50)$. Due to compromised neurology, intravenous fluids were restricted to $50 \mathrm{mls} / \mathrm{kg} /$ day but were changed to $10 \%$ dextrose. Further neurological compromise occurred on day three when he had bilateral fixed and dilated pupils of $7 \mathrm{~mm}$ diameter. Repeat CT Brain revealed worsening cerebral oedema (Fig. 2a). A trans-cranial bolt was surgically applied with an opening pressure of $30 \mathrm{mmHg}$. $600 \mathrm{mg} / \mathrm{kg} /$ day of S DL-3OHB was commenced on day four of hospital admission in tandem with attempts to provide higher energy enteral nutrition as indicated in Table 1b. Aetoacetate measurement increased to $0.11 \mathrm{mmol} / \mathrm{L}$ and betahydroxybutyrate to $0.08 \mathrm{mmol} / \mathrm{L}$. Intracranial pressure continued to fluctuate over the subsequent three days but he gradually began to recover, self-ventilating in air by day twenty-four and being discharged home independently 
Table 1 Energy delivery for each case per day of admission in intensive care, separated as IV (intravenous) and estimated food energy and total for case 1a, CACTD, 1b HMGCL2D and 1c CPT2D. Estimated energy requirement for neonates and infants is 100 $\mathrm{Kcal} / \mathrm{Kg} /$ day and for adolescent case 1B approximately $50 \mathrm{Kcals} / \mathrm{Kg} /$ day

\begin{tabular}{|c|c|c|c|c|c|c|c|}
\hline \multicolumn{8}{|l|}{ a } \\
\hline Day & 4 & 5 & 6 & 7 & 8 & 9 & 10 \\
\hline IV Energy (Kcal) & 45 & 110 & 95 & 84 & 38 & 16 & 100 \\
\hline Food energy (Kcal) & & 11 & 27 & 76 & 172 & 206 & 29 \\
\hline Total energy (Kcal) & 45 & 121 & 122 & 160 & 210 & 222 & 128 \\
\hline $\mathrm{Kcal} / \mathrm{Kg}$ & 17 & 47 & 47 & 62 & 81 & 85 & 49 \\
\hline D,L-3-OHB (mg/kg/day) & & 300 & 600 & 600 & 600 & 600 & 600 \\
\hline \multicolumn{8}{|l|}{$b$} \\
\hline Day & 1 & 2 & 3 & 4 & 5 & 6 & 7 \\
\hline IV Energy (Kcal) & 200 & 510 & 340 & 200 & 0 & 0 & 0 \\
\hline Food energy (Kcal) & 0 & 250 & 1500 & 2090 & 1680 & 2500 & 2500 \\
\hline Total energy (Kcal) & 200 & 760 & 1840 & 2290 & 1680 & 2500 & 2500 \\
\hline $\mathrm{Kcal} / \mathrm{Kg}$ & 4 & 15 & 37 & 46 & 34 & 50 & 50 \\
\hline D,L-3-OHB (mg/kg/day) & 0 & 0 & 0 & 600 & 600 & 600 & 600 \\
\hline \multicolumn{8}{|l|}{ c } \\
\hline Day & 1 (12 h after admission & 2 & 3 & 4 & 5 & 6 & 7 \\
\hline IV Energy (Kcal) & 84 & 76 & 0 & 100 & 0 & 0 & 0 \\
\hline Food energy (Kcal) & 11 & 427 & 517 & 442 & 550 & 551 & 472 \\
\hline Total energy (Kcal) & 95 & 503 & 517 & 542 & 550 & 551 & 472 \\
\hline $\mathrm{Kcal} / \mathrm{Kg}$ & 21 & 109 & 112 & 118 & 120 & 120 & 103 \\
\hline D,L-3-OHB (mg/kg/day) & 330 & 978 & 815 & 978 & 978 & 978 & 815 \\
\hline
\end{tabular}

ambulatory by day sixty-three. MRI of the brain indicated that he had suffered extensive posterior-circulation infarction, presumed to be due to herniation into the foramen magnum at pressure, and he continues to have complete cortical blindness. Extensive white matter abnormalities were demonstrated at the time of his presentation and persisted three years later on repeat scanning (Fig. $2 \mathrm{~b}$ and $\mathrm{c}$ ). The remainder of his neurology remains normal aged 24 years.

\section{Case 3}

Case 3 is the first child of non-consanguineous parents from Syria. She was diagnosed at 3 weeks of age after borderline newborn screening results indicative of CACTD or CPT2D at which time, she was thriving on exclusive breast feeds. Skin fibroblast, white cell enzymology and genetic testing was initiated and subsequently confirmed CPT2D with leucocyte activity being 3\% relative to controls. The baby was discharged on a feeding regimen comprising $1 / 3$ of total energy from MCT and $2 / 3$ from breast feeds. At three months of age, over a 48 $\mathrm{h}$ period, the baby started refusing MCT based bottle feeds. On the morning of admission, the baby had two vomits over a six hour period and was advised to attend the emergency department (ED). She was assessed in ED to be lethargic but alert with her heart rate of 140 beats per minute (BPM) and core temperature being 37 degrees. Her venous blood gas demonstrated a whole blood glucose level of $1.5 \mathrm{mmol} / \mathrm{L}, \mathrm{pH} 7.40, \mathrm{pCO} 227$ $\mathrm{mmHg}$, and base excess of -7.1 She was treated with two consecutive boluses of $2 \mathrm{ml} / \mathrm{kg} 10 \%$ dextrose and placed on $150 \%$ standard maintenance $10 \%$ dextrose and normal saline. Two hours after admission she suddenly became flaccid and unresponsive to pain with a core temperature of 32.6 degrees and heart rate of 100 BPM. Pupils were reactive, the fontanelle not bulging, but there was sustained clonus $>15$ beats bilaterally. Venous whole blood glucose was normal at $6.6 \mathrm{mmol} / \mathrm{L}$ with serum ammonia subsequently reported to be $300 \mu \mathrm{mol} / \mathrm{L}$ (10-80).) Bedside beta-hydroxybutyrate measurement was $<0.2 \mathrm{mmol} / \mathrm{L}$ and contemporary measurements of free fatty acid was $3.96 \mathrm{mmol} / \mathrm{L}$ with laboratory betahydroxybuyrate of $<0.18 \mathrm{mmol} / \mathrm{L}$ (ratio $>20$ implying hypoketosis). Echocardiography performed in the emergency department showed mild septal hypertrophy with no significant cardiac dysfunction. She had clinical evidence of hepatomegaly. After fluid resuscitation and empirical use of intravenous antibiotics, the baby was administered $150 \mathrm{mg} / \mathrm{kg} /$ dose of S DL-3-OHB four hourly with the first dose administered less than three 

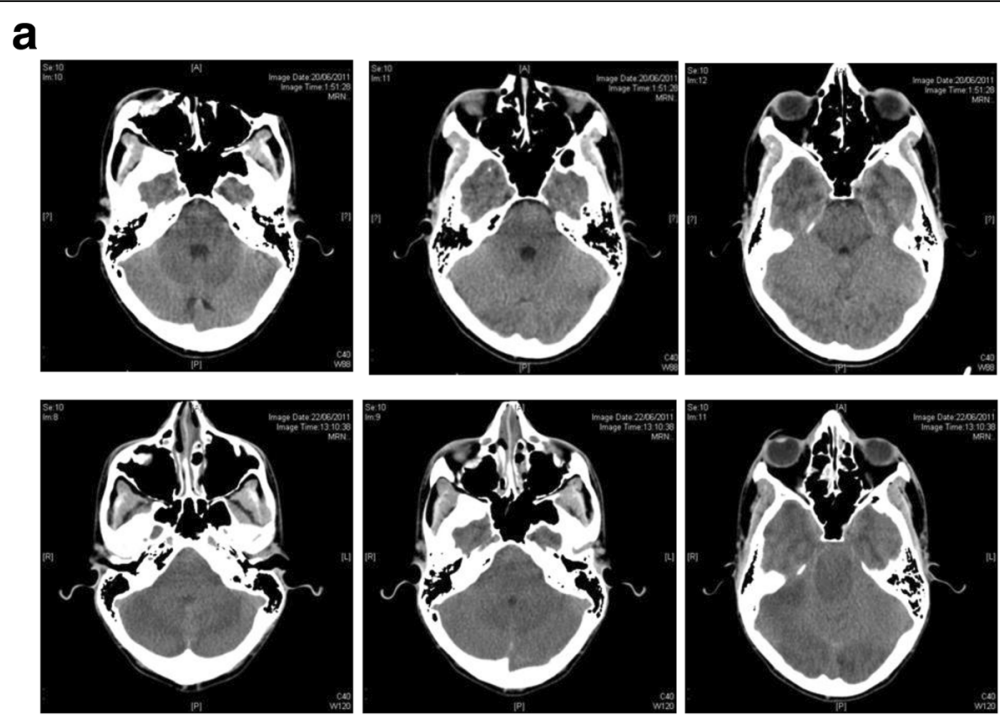

b

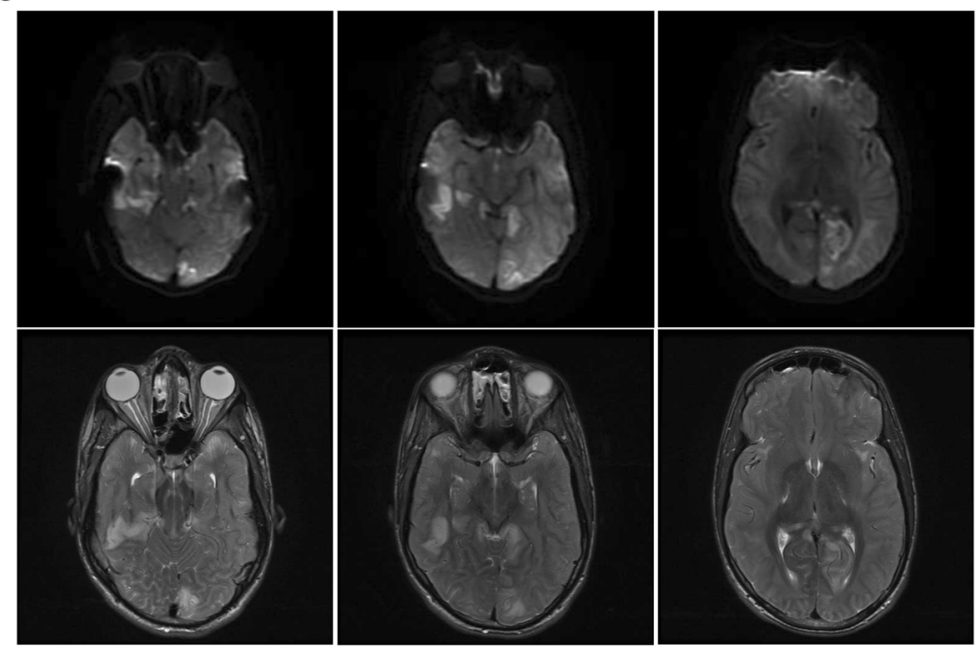

C
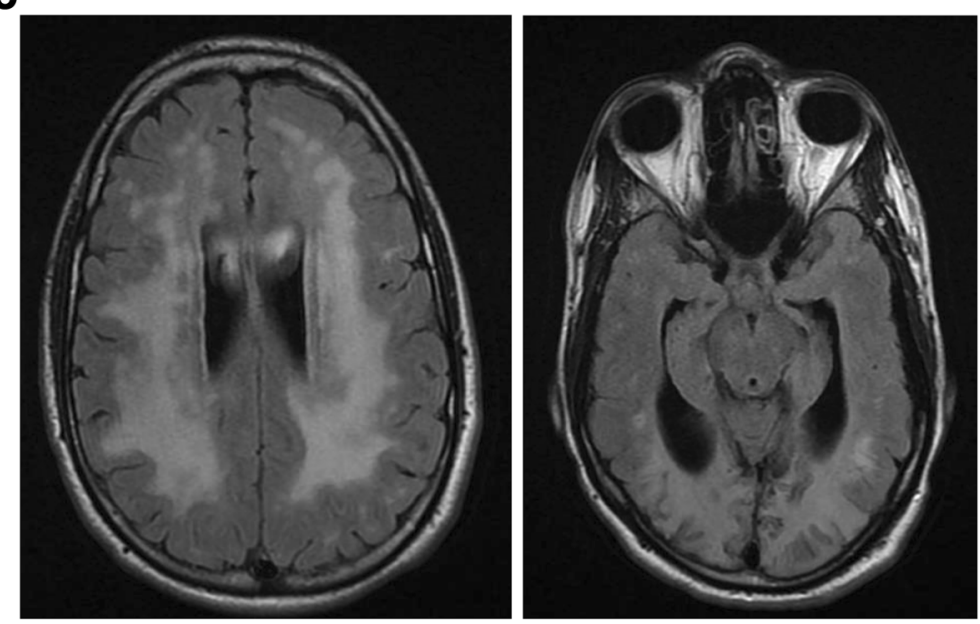

Fig. 2 (See legend on next page.) 
(See figure on previous page.)

Fig. 2 a) CT Scan of 16 yr old boy with HMGCL2D on day 1 of admission (top row) when GCS was 10 and on day 3 (bottom row) when GCS was 3 , and pupils were dilated bilaterally indicating deteriorating cerebral oedema. b) Axial DWI (top row) and T2 (bottom row) images of $16 \mathrm{yr}$ old boy with HMGCL2D on day 3 of admission when GCS was 3. There is infarction involving the occipital and temporal lobes, likely secondary to trans-tentorial herniation and compression of the posterior cerebral arteries. Note also the distended optic nerve sheaths and flattening of the posterior globes, in keeping with significantly elevated intracranial pressure. c) Axial T2 Flair images of case 2 with HMGCLD three years after acute life-threatening event (aged 19 years) continuing to demonstrate deep subcortical white matter abnormality with extensive occipital lobe changes leading to cortical blindness

hours after the hypothermia event (Table 1c). After twelve hours and three doses of S DL-3-OHB, the baby was awake and beginning to suck with the neurological examination being normal after a further $24 \mathrm{~h}$. Because of the rapid neurological recovery, brain MRI was delayed until one month showing some prominence in frontal extra-axial space, but was otherwise normal (Fig. 3). At one year of age of age, at last review, development was within normal limits being able to pull to stand and standing with support but she does have peripheral hypertonia.. Nonetheless her neurological prognosis remains guarded.

\section{Discussion}

The outcome of severely sick patients with these disorders is dire in the published literature. There are several

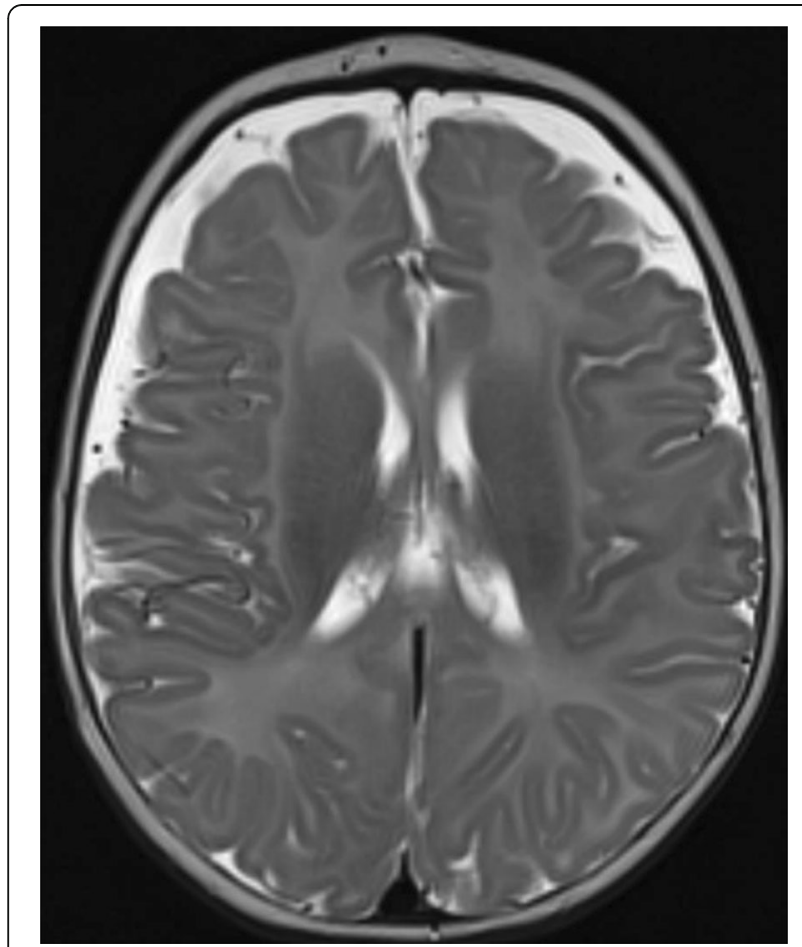

Fig. 3 Axial FLAIR image of the brain of case 3 with CPT2D performed at four months of age, one month following her acute decompensation event. Selected image at the level of the lateral ventricles demonstrates prominence of the extra-axial CSF spaces overlying the frontal lobes. Myelin appearance is appropriate for age reports of deaths due to rapidly progressing encephalopathy occurring with decompensation in HMGCLD during adult life, sometimes unexpectedly in previously well individuals [7, 8] [17]. Many cases in earlier series either died or had severe cognitive sequelae. White matter abnormalities are common in this condition although the manifestation does not always correlate with disease course $[7,18]$. .Survival in early onset CACT deficiency is rare $[4,19,20]$. Multi-organ failure and death is the usual reported outcome. CP2D is more commonly manifest as an adult form with recurrent rhabdomyolysis, but severe neonatal and infantile forms are well described [21-23]. Sudden death, cardiomyopathy, hypoketotic hypoglycaemia and acute encephalopathy with hyperammonaemia are well described similar to other MFAO disorders.

For all these conditions, patients may enter a vicious cycle of catabolism from which it is often difficult to recover. Catabolism triggers a cascade of issues incorporating accumulation of potentially toxic substrates such as long chain acyl-carnitines and/or failure to generate crucial ketones. For organs in energy deficit, failure to generate ketones compounds critical energy requirements as indicated by these dramatic cases. The third case is interesting in that the encephalopathy occurred after hypoglycaemia was corrected at a time when there was satisfactory glucose provision indicating that an alternate energy source to glucose is required in these instances [24]. This supports the hypothesis that glucose alone is not sufficient to provide cerebral energy requirements in infants [25]. There are data to suggest that both lactate and ketones also play a vital role [26-28].

When patients with MFAO disorders or KB synthetic dysfunction decompensate, the aim is to restore homeostasis, but this is limited by technical difficulties of doing so in critically sick individuals. Often the preferred enteral route may not be effective for macronutrients in the face of persistent vomiting, absorption difficulties and intolerance. As these individuals fluctuate in consciousness, they pose an increasing aspiration risk and hence feeds may be discontinued for protracted periods of time as occurred in these cases. Finally, intravenous therapy has to be restricted in volume as cerebral oedema worsens, as seen dramatically in the second case. Resting energy expenditure studies have demonstrated adult requirements for 
glucose are approximately $2.5 \mathrm{mg} / \mathrm{kg} / \mathrm{min}$ [29]. This equates to approximately $2500 \mathrm{ml}$ of $10 \%$ dextrose required for an average adult. In a metabolic crisis, significantly more energy will be required. Consequently, fluid restriction compromises energy delivery further. Cytotoxin related cerebral oedema is common in metabolic conditions and thus cerebellar tonsillar herniation is a real risk. Hence it is imperative that treating physicians comanage optimal energy requirements in conjunction with fluid restrictions, neurological, cardiological and ventilation requirements.

The precedent for the use of S DL-3-OHB has been demonstrated in multiple acyl co-A dehydrogenase deficiency, in which there are several anomalies in mitochondrial ATP production The original paper by van Hove et al. indicated improvement in neurological and cardiac parameters as also seen in our patient with CACT deficiency. Neurological improvements have been reported in other cases using physiological doses of $\mathrm{S}$ DL-3OHB, and it has also been successfully used in the glycogen storage disorders to rescue cardiomyopathy [30]. There are experimental data in both animals and humans suggesting that both organs are primed to utilise energy from ketones more effectively in the catabolic state $[31,32]$. In the immature brain, ketones can promote myelin production [33]. Whilst cytoplasmic synthesis of mevalonate from HMG Co-A is known to be integral to cholesterol synthesis. There are rat data to suggest that acetoacetate and 3-hydroxybutyrate also may have a significant effect $[34,35]$. Hence the MRI findings of significant white matter changes in many cases of HMGLD can be explained by KB deficiency [18]. This hypothesis is yet to be tested fully because the myelin may appear abnormal but does not necessary correlate with function and the composition of this "abnormal" myelin is not clearly understood. In our neonatal CACTD case there is remarkable improvement in myelination across the disease course (Fig. 1b) with therapy in contrast to the HMGCLD case (Fig. 1d).

Stable isotope studies of ketone bodies in neonates indicate that up to $10 \mathrm{kcal} / \mathrm{kg}$ of neonatal energy requirements can come from ketones - despite a regular four hourly enteral feeding regimen [24]. The studies estimate that $2-3 \mathrm{~g} / \mathrm{kg} /$ day are transported and likely utilised. These studies are performed in steady state and hence requirements and utilisation could increase in catabolic situations. Racemic S DL-3-OHB comprises D and $\mathrm{L}$ stereoisomers of 3-hydroxybutyrate. In terms of energy delivery calculations from S DL-3-OHB, it is difficult to calculate this from the racemic mixture. There have been stable isotope studies in neonates utilising and measuring metabolism of the D-stereoisomer. Similarly clinical studies typically measure the D-isomer even when the racemic mixture has been administered [36].
Studies performed in infant rats indicate that both forms are utilised with a preponderance to utilise the Lstereoisomer for myelin synthesis. Hence, it is difficult to determine from this study the extent to which the different stereoisomers are oxidised or utilised in myelination. In this study pre and post dose ketone measurements were taken before and after treatment for two patients but it is difficult to know when and what samples should be taken as the pharmacokinetics of the $\mathrm{S}$ DL-3OHB is not known.

The neonatal brain has relatively high energy requirements, compared to adults and other animals. In a fasting or catabolic state, failure to generate ketones leads to impaired gluconeogenesis which compounds metabolic compromise. At such times, exogenous glucose can rarely be delivered in sufficient quantities to ameliorate energy deficit. Excessive intravenous glucose delivery can perpetuate cerebral oedema and lead to osmotic diuresis leading to further compromise. Providing ketones as a sodium salt can redress this balance whilst also providing an alternative energy substrate that can be utilised by the brain.

Whilst the contemporary use of ketones in this study are suggestive of improvement in clinical conditions, this cannot be proven in this open label uncontrolled study.

Ketogenic diets have become more prevalent in the general community and in specific situations to improve cerebral health such as in pyruvate dehydrogenase complex and GLUT 1 deficiencies as well as generalised epilepsy and Alzheimer's disease [37-41]. The conditions in this paper are all inherited hypoketotic disorders and hence would deteriorate with a standard ketogenic diet. Nonetheless they demonstrate utility of ketones in acute brain dysfunction which may extrapolate to other situations where there is no IEM.

\section{Conclusion}

This paper demonstrates adjunctive treatment with $\mathrm{S}$ DL-3-OHB in severe metabolic decompensation of 3 patients in energy deficit with HMGCLD, CACTD and CPT2D. Their rapidly declining function was recovered with standard treatment and the use of S-DL-3OHB which has led to sustained long-term neurological recovery. This therapy can be considered in instances of impaired ketone production in other critically sick individuals. It is important for investigators utilising such treatment to carefully correlate changes in clinical events with biomarkers to determine efficacy. Ketones may be an adjunctive therapy for other non IEM neurological crises.

\section{Abbreviations}

BCA: Bicinchoninic assay; BPM: Beats per minute; CACTD: Carnitine-acylcarnitine translocase deficiency; CPT2D: Carnitine palmitoyl transferase ॥ deficiency; CT: Computed tomography; ED: Emergency department;

FDA: Food and Drugs Administration; GC/MS: Gas chromatography mass 
spectrometry; GCS: Glasgow Coma Scale; HMGCLD: 3-hydroxyl, 3-methyl, glutaryl CoA lyase deficiency; IEM: Inborn errors of metabolism; KB: Ketone Bodies; MADD: Multiple acyl co A dehydrogenase deficiency; MCT: Medium chain triglyceride; MFAOD: Mitochondrial fatty acid oxidation; MRI: Magnetic resonance image; S DL-3-OHB: Sodium DL-3-hydroxybutyrate; TGA: Therapeutic Goods Administration; UPLC-MS/MS: Ultra-high performance liquid chromatography-tandem mass spectrometry

\section{Acknowledgements}

The authors would like to acknowledge care provided in emergency departments, neonatal and intensive care units for these patients at St George Hospital, Kogarah, NSW and The Children's Hospital at Westmead, NSW. We would also like to acknowledge care provided by other members of the metabolic team including Barbara Dennison, John Christodoulou, Carolyn Ellaway and lan Alexander.

\section{Authors' contributions}

KB wrote the manuscript first draft and subsequent edits. WM and MT are the primary physicians managing case 2 and have contributed to the manuscript. ST provided and analysed dietary data and reference energy content within the manuscript and in clinical practice. TD was involved in the clinical care of all 3 patients and helped avail sodium D, L 3 Hydroxybutyrate, contributing to final draft. AT and BD performed diagnostic analyses on all 3 patients, contributing to methodology of this study and final draft. The author(s) read and approved the final manuscript

\section{Funding}

No funding was provided for this study.

\section{Availability of data and materials}

Not applicable.

\section{Ethics approval and consent to participate}

This study was approved by the human research ethics committee of Sydney Children's Hospital Network.

\section{Consent for publication}

All participants have provided written informed consent to participate.

\section{Competing interests}

The authors declare no competing interests.

\section{Author details}

${ }^{1}$ Disciplines of Genetic Medicine and Child and Adolescent Health, University of Sydney, Sydney, Australia. ${ }^{2}$ Genetic Metabolic Disorders Service, Sydney Children's Hospital Network, Children's Hospital at Westmead, Locked Bag 4001, Westmead, NSW 2145, Australia. ${ }^{3}$ Department of Neurology, St George Hospital, Kogarah, NSW, Australia. ${ }^{4}$ NSW Biochemical Genetics Service, Westmead, NSW, Australia. ${ }^{5}$ Westmead Hospital, University of Sydney, Westmead, Australia.

\section{Received: 23 September 2019 Accepted: 24 January 2020} Published online: 18 February 2020

\section{References}

1. Berg JMTJ, Stryer L. Biochemistry. New York: W H Freeman; 2005. Available from: https://www.ncbi.n/m.nih.gov/books/NBK22553/

2. Morris AA. Cerebral ketone body metabolism. J Inherit Metab Dis. 2005; 28(2):109-21.

3. Rubio-Gozalbo ME, Bakker JA, Waterham HR, Wanders RJ. Carnitineacylcarnitine translocase deficiency, clinical, biochemical and genetic aspects. Mol Asp Med. 2004;25(5-6):521-32.

4. Al-Sannaa NA, Cheriyan GM. Carnitine-acylcarnitine translocase deficiency. Clinical course of three Saudi children with a severe phenotype. Saudi Med J. 2010;31(8):931-4.

5. lacobazzi V, Pasquali M, Singh R, Matern D, Rinaldo P. Amat di san Filippo C, et al. response to therapy in carnitine/acylcarnitine translocase (CACT) deficiency due to a novel missense mutation. Am J Med Genet A. 2004; 126A(2):150-5. https://doi.org/10.1002/ajmg.a.20573.
6. Longo N. Amat di san Filippo C, Pasquali M. disorders of carnitine transport and the carnitine cycle. Am J Med Genet C Semin Med Genet. 2006;142C(2): 77-85. https://doi.org/10.1002/ajmg.c.30087.

7. Grunert SC, Schlatter SM, Schmitt RN, Gemperle-Britschgi C, Mrazova L, Balci MC, et al. 3-Hydroxy-3-methylglutaryl-coenzyme a lyase deficiency: clinical presentation and outcome in a series of 37 patients. Mol Genet Metab. 2017;121(3):206-15. https://doi.org/10.1016/j.ymgme.2017.05.014. Epub May 22.

8. Al-Sayed M, Imtiaz F, Alsmadi OA, Rashed MS, Meyer BF. Mutations underlying 3-hydroxy-3-methylglutaryl CoA lyase deficiency in the Saudi population. BMC Med Genet. 2006;7:86.

9. Fukao T, Mitchell G, Sass JO, Hori T, Orii K, Aoyama Y. Ketone body metabolism and its defects. J Inherit Metab Dis. 2014;37(4):541-51. https:// doi.org/10.1007/s10545-014-9704-9 Epub 2014 Apr 8.

10. Van Hove JL, Grunewald S, Jaeken J, Demaerel P, Declercq PE, Bourdoux P, et al. D,L-3-hydroxybutyrate treatment of multiple acyl-CoA dehydrogenase deficiency (MADD). Lancet. 2003;361(9367):1433-5.

11. Chalmers R, Lawson A. Gas chromatography-mass spectrometry. Organic acids in man : analytical chemistry, biochemistry, and diagnosis of the organic acidurias London, New York: Chapman and Hall; 1982. p. 83-127.

12. Goodman SI, Markey SP. Diagnosis of organic acidemias by gas chromatographymass spectrometry. Lab Res Methods Biol Med. 1981;6:1-158.

13. Millington DS, Kodo N, Norwood DL, Roe CR. Tandem mass spectrometry: a new method for acylcarnitine profiling with potential for neonatal screening for inborn errors of metabolism. J Inherit Metab Dis. 1990;13(3): 321-4. https://doi.org/10.1007/bf01799385.

14. Rashed MS, Bucknall MP, Little D, Awad A, Jacob M, Alamoudi M, et al. Screening blood spots for inborn errors of metabolism by electrospray tandem mass spectrometry with a microplate batch process and a computer algorithm for automated flagging of abnormal profiles. Clin Chem. 1997:43(7):1129-41.

15. Demaugre F, Bonnefont JP, Cepanec C, Scholte J, Saudubray JM, Leroux JP. Immunoquantitative analysis of human carnitine palmitoyltransferase I and II defects. Pediatr Res. 1990;27(5):497-500. https://doi.org/10.1203/00006450199005000-00016.

16. Goldschmidt RC, Kimelberg HK. Protein analysis of mammalian cells in monolayer culture using the bicinchoninic assay. Anal Biochem. 1989;177(1): 41-5. https://doi.org/10.1016/0003-2697(89)90010-9.

17. Langendonk JG, Roos JC, Angus L, Williams M, Karstens FP, de Klerk JB, et al. A series of pregnancies in women with inherited metabolic disease. J Inherit Metab Dis. 2012;35(3):419-24. https://doi.org/10.1007/s10545-0119389-2 Epub 2011 Sep 15.

18. van der Knaap MS, Bakker HD, Valk J. MR imaging and proton spectroscopy in 3-hydroxy-3-methylglutaryl coenzyme a lyase deficiency. AJNR Am J Neuroradiol. 1998;19(2):378-82.

19. Mahapatra S, Ananth A, Baugh N, Damian M, Enns GM. Triheptanoin: A Rescue Therapy for Cardiogenic Shock in Carnitine-acylcarnitine Translocase Deficiency. JIMD reports. 2018:39:19-23.(doi):https://doi.org/10.1007/8904_ 2017_36. Epub Jul 9.

20. Vitoria I, Martin-Hernandez E, Pena-Quintana L, Bueno M, Quijada-Fraile P, Dalmau J, et al. Carnitine-acylcarnitine translocase deficiency: experience with four cases in Spain and review of the literature. JIMD Rep. 2015;20:1120.(doi):https://doi.org/10.1007/8904_2014_382. Epub 5 Jan 23.

21. Joshi PR, Deschauer M, Zierz S. Carnitine palmitoyltransferase II (CPT II) deficiency: genotype-phenotype analysis of 50 patients. J Neurol Sci. 2014; 338(1-2):107-11. https://doi.org/10.1016/j.jns.2013.12.026. Epub Dec 23.

22. Fanin M, Anichini A, Cassandrini D, Fiorillo C, Scapolan S, Minetti C, et al. Allelic and phenotypic heterogeneity in 49 Italian patients with the muscle form of CPT-II deficiency. Clin Genet. 2012;82(3):232-9. https://doi.org/10. 1111/j.399-0004.2011.01786.x Epub 2011 Oct 12.

23. Thuillier L, Rostane H, Droin V, Demaugre F, Brivet M, Kadhom N, et al. Correlation between genotype, metabolic data, and clinical presentation in carnitine palmitoyltransferase 2 (CPT2) deficiency. Hum Mutat. 2003;21(5): 493-501. https://doi.org/10.1002/humu.10201.

24. Bougneres PF, Lemmel C, Ferre P, Bier DM. Ketone body transport in the human neonate and infant. J Clin Invest. 1986;77(1):42-8. https://doi.org/10. 1172/JCl112299.

25. Hui S, Ghergurovich JM, Morscher RJ, Jang C, Teng X, Lu W, et al. Glucose feeds the TCA cycle via circulating lactate. Nature. 2017;551(7678):115-8. https://doi.org/10.1038/nature24057 Epub 2017 Oct 18.

26. Fernandes J, Pikaar NA. Ketosis in hepatic glycogenosis. Arch Dis Child. 1972;47(251):41-6 
27. Vining EP, Freeman JM, Ballaban-Gil K, Camfield CS, Camfield PR, Holmes GL, et al. A multicenter study of the efficacy of the ketogenic diet. Arch Neurol. 1998;55(11):1433-7.

28. Bowman CE, Scafidi J, Scafidi S. Metabolic perturbations after pediatric TBI: It's not just about glucose. Exp Neurol. 2019;316:74-84.(doi):https://doi.org/ 10.1016/j.expneurol.2019.03.018. Epub Apr 3.

29. Bier DM, Leake RD, Haymond MW, Arnold K, Gruenke LD, Sperling MA, et al. Measurement of "true" glucose production rates in infancy and childhood with 6,6-dideuteroglucose. Diabetes. 1977;26(11):1016-23.

30. Valayannopoulos V, Bajolle F, Arnoux JB, Dubois S, Sannier N, Baussan C, et al. Successful treatment of severe cardiomyopathy in glycogen storage disease type III With D,L-3-hydroxybutyrate, ketogenic and high-protein diet. Pediatr Res. 2011;70(6):638-41.

31. Hussain K, Eaton S, Clayton P. Exogenous administered DL- sodium betahydroxybutyrate (beta-OHB) can cross the blood brain barrier. Pediatr Res. 2003;53(5):865; author reply -6 .

32. Giudetti AM, Stanca E, Siculella L, Gnoni GV, Damiano F. Nutritional and Hormonal Regulation of Citrate and Carnitine/Acylcarnitine Transporters: Two Mitochondrial Carriers Involved in Fatty Acid Metabolism. Int J Mol Sci. 2016;17(6).(pii):E817. doi: https://doi.org/10.3390/ijms17060817.

33. Van Hove JL, Grunewald S, Jaeken J, Demaerel P, Declercq PE, Bourdoux P, et al. D,L-3-hydroxybutyrate treatment of multiple acyl-CoA dehydrogenase deficiency (MADD). Lancet (London, England). 2003;361(9367):1433-5.

34. Edmond J. Ketone bodies as precursors of sterols and fatty acids in the developing rat. J Biol Chem. 1974;249(1):72-80.

35. Bergstrom JD, Wong GA, Edwards PA, Edmond J. The regulation of acetoacetyl-CoA synthetase activity by modulators of cholesterol synthesis in vivo and the utilization of acetoacetate for cholesterogenesis. J Biol Chem. 1984;259(23):14548-53.

36. Fischer T, Och U, Klawon I, Och T, Gruneberg M, Fobker M, et al. Effect of a Sodium and Calcium DL-beta-Hydroxybutyrate Salt in Healthy Adults. J Nutr Metab. 2018;2018:9812806.(doi):https://doi.org/10.1155/2018/9812806. eCollection 2018.

37. Pong AW, Geary BR, Engelstad KM, Natarajan A, Yang H, De Vivo DC Glucose transporter type I deficiency syndrome: epilepsy phenotypes and outcomes. Epilepsia. 2012;53(9):1503-10.

38. Barnerias C, Saudubray JM, Touati G, De Lonlay P, Dulac O, Ponsot G, et al. Pyruvate dehydrogenase complex deficiency: four neurological phenotypes with differing pathogenesis. Dev Med Child Neurol. 2010;52(2):e1-9.

39. Wolf NI, Bast T, Surtees R. Epilepsy in inborn errors of metabolism. Epileptic disorders : international epilepsy journal with videotape. 2005;7(2):67-81.

40. Freeman JM, Vining EP, Kossoff EH, Pyzik PL, Ye X, Goodman SN. A blinded crossover study of the efficacy of the ketogenic diet. Epilepsia. 2009;50(2): 322-5. https://doi.org/10.1111/.528-67.2008.01740.x Epub 2008 Aug 19.

41. Fortier M, Castellano CA, Croteau E, Langlois F, Bocti C, St-Pierre V, et al. A ketogenic drink improves brain energy and some measures of cognition in mild cognitive impairment. Alzheimers Dement. 2019;28(19):30011.

\section{Publisher's Note}

Springer Nature remains neutral with regard to jurisdictional claims in published maps and institutional affiliations.

Ready to submit your research? Choose BMC and benefit from:

- fast, convenient online submission

- thorough peer review by experienced researchers in your field

- rapid publication on acceptance

- support for research data, including large and complex data types

- gold Open Access which fosters wider collaboration and increased citations

- maximum visibility for your research: over $100 \mathrm{M}$ website views per year

At $\mathrm{BMC}$, research is always in progress.

Learn more biomedcentral.com/submissions 